\title{
Observations on quality in the PhD supervision experience
}

\author{
Barbara M. Savage \\ Portsmouth Business School, \\ University of Portsmouth, \\ Richmond Building, Portland Street, \\ Portsmouth PO1 3DE, UK \\ Fax: +44-23-9284-4037 \\ E-mail: Barbara.Savage@port.ac.uk
}

\begin{abstract}
The $\mathrm{PhD}$ is a key step in academic development and the training of the next generation of researchers. However, in this age of control and regulation, it remains an outpost of individualism and variation. This paper sets out to explore the issues that surround the supervisory activity and attempts to draw some tentative conclusions about points that may enhance the likelihood of a good outcome for both student and supervisor. It also considers the identification of indicators that may provide early warning of problems. This paper is based on the personal experiences of the author with over 19 years of $\mathrm{PhD}$ supervision, supplemented by her observations of the experiences of colleagues and their students. These observations will be contrasted with the findings of other researchers. As such, the paper is presented as a starting point for discussion and future research.
\end{abstract}

Keywords: doctoral supervision; quality enhancement; supervisory relationships; student support; supervisor development; stakeholders.

Reference to this paper should be made as follows: Savage, B.M. (2013) 'Observations on quality in the $\mathrm{PhD}$ supervision experience', Int. J. Information and Operations Management Education, Vol. 5, No. 2, pp.190-204.

Biographical notes: Barbara M. Savage has spent all of her 30-year career in the academia. Having worked at one UK university for 27 years, in 2010, she moved to the Portsmouth Business School. She is an experienced Course Developer and leader who has been involved in a range of degrees across the management, engineering and information systems domains. Her research interests relate to business excellence, quality and knowledge management. She has supervised a large number of $\mathrm{PhD}$, Masters and undergraduate student research projects since 1993 .

\section{Introduction and methodology}

The $\mathrm{PhD}$ is the highest level of academic study offered by universities and is seen as the pinnacle of academic achievement for young researchers, yet it is also possibly the least understood type of academic study. This paper centres on the hypothesis that doctoral study should be viewed as a service. So for satisfactory outcomes to be achieved, both for 
the individual student and in the long term, it is necessary for doctoral supervision to be seen as a quality experience by both student and supervisor, so that the 'customer' (student) goes away happy and the 'supplier' (supervisor) perceives the activity as one that provides a worthwhile return for their efforts. Taking a service viewpoint, there are several significant phases that must be carefully handled to bring a successful outcome. These are:

1 establishing the customer-supplier relationship

2 deciding what both parties want from the service

3 agreeing service delivery approaches

4 delivering/receiving the service.

Thus this paper draws on the author's personal supervisory experience to attempt to identify some key touch points in the $\mathrm{PhD}$ service activity that may impact on the perception of quality by those involved, even though this is a highly subjective concept for which there is no obvious quantitative measure. It does not, however, directly address pedagogical issues, nor does it consider how these points might influence the standard of the thesis. Clearly, a good experience is vital for the future of the student and, by implication, the next generation of researchers, but if $\mathrm{PhD}$ supervision is not also satisfying and rewarding, then academics will become disinclined to participate, thus depriving potential students of the opportunity to work with experienced researchers and to learn from them.

The paper is based on a longitudinal case study of a single academic's doctoral supervision career. Within this is a collection of sub-cases that are the students that were supervised. The study covers 19 years of supervision at two UK universities, plus examining at several others and encompasses 18 students working in the operations and quality management domains. While, in the main, the supervisions have been successful, in a few cases there have been problems and disappointments. Two students are still actively pursuing their studies.

This is a participant-observer analysis, with the author being a 'complete participant' under Gold's Classification (Bryman and Bell, 2011). However, it must be considered to be a post-hoc reflection on past experience, rather than a purposive, pre-planned research study; an attempt to derive meaning from experience, rather than data gathering via a structured research activity. Clearly, both of these factors significantly impact on repeatability of the study.

Though this case is an actual instance of a doctoral supervision career, it is questionable whether it is representative of such careers in general, even for UK-based academics, since it is difficult to establish a 'typical' profile for doctoral students supervised by any given academic. In this case, the group is obviously bi-polar in terms of background and study mode. Thus, while it is hoped that the observations made herein will be of value to other supervisors, it cannot be supposed that they are truly generalisable because of the nature of the data set. Descriptive statistics for the case are shown in the appendix.

The fact that this paper does not commence with a literature review, as is the norm for the majority of papers, is quite deliberate. This is because the research strategy adopted is inductive, so that the goal is to attempt to extract learning points from the case upon which to build theory, rather than to try to find evidence in the case to confirm or refute 
established theory. Hence, to start from the literature would prejudice the analysis by establishing a list of features that might be expected to be present, thus raising the visibility of these in comparison to others actually present in the case study, but not suggested by the literature.

\section{What is quality?}

ISO 8402 (ISO, 1994) defined quality as "the totality of features and characteristics of a product or service that bear on its ability to satisfy a given need". In the context of a $\mathrm{PhD}$, this definition fits well because of the openness of its final phrase. Whereas many other definitions of quality focus primarily on satisfying the customer's needs, this one gives the opportunity to take a more holistic view that encompasses the needs of all the stakeholders involved and so has particular relevance to the $\mathrm{PhD}$. Stakeholder roles will be discussed later.

\section{Quality in services in the context of the $\mathrm{PhD}$}

While both products and services fall within the scope of quality management, they cannot always be considered in the same way. Lewis (2007) and Bergman and Klefsjö (1994) have explored the characteristics that differentiate services from products in the context of quality. Several of these characteristics are of significance in the context of the $\mathrm{PhD}$.

\subsection{Intangibility}

"Services are intangible and may be difficult for a supplier to explain and specify and sometimes also difficult for a customer to assess" (Bergman and Klefsjö, 1994). Thus there may be gaps between the customer's expectations and the supplier's perception of those expectations. Additionally, service specifications may differ from what the customer anticipates because of a lack of knowledge of, for example, regulatory controls that are imposed upon the supplier in respect of a particular service (Lewis, 2007).

The fact that there is an element of myth about what a $\mathrm{PhD}$ is and what is entailed in earning it means that there is often an initial mismatch in understanding and expectation between student and supervisors. If this is not exposed and explored so that a common view can be achieved, there is a very real risk that the success of the whole process will be undermined. One facet of this myth is the belief that, because the $\mathrm{PhD}$ is the highest level of academic study, the topic being investigated must therefore be likely to result in some major contribution to knowledge or a significant leap in understanding. Hence, the proposed project has an enormous scope that would require a large team of researchers working over many years with a sizeable budget, rather than the efforts of a single research student within the time and resource constraints of a PhD. So, typically, part of the acceptance process and early supervision for a new PhD student will need to focus on bringing the student to understand that a $\mathrm{PhD}$ is more about training in the research process and associated skills, than in the delivery of world-changing outcomes and that, while novelty and contribution to knowledge are a requirement, it is more important for these to be solidly justified by the work done, than for them to be wide-ranging. To quote 
a respondent to Mullins and Kiley's (2002) study of $\mathrm{PhD}$ examiners: 'A PhD is three years of solid work, not a Nobel Prize'. This statement neatly counters another element of the myth: that a $\mathrm{PhD}$ is very difficult.

Another factor that may result in mismatched expectations is when the student is returning to study as a mature student after gaining a considerable amount of industrial experience, because their understanding of what research is and what is appropriate content for a research report may be very different from the academic view. It is very likely that they will have honed skills in succinct report writing and the delivery of results by presentation of overheads and will have long since ceased to prepare in-depth, evidence-based, written arguments. Therefore a key aspect of the supervisory process is the active encouragement of the (re)development of writing skills. If this need is not recognised by the supervisor, it may lead to frustration on both sides because of a lack of common understanding that can be difficult to reconcile.

\subsection{Customer (student) involvement}

In the $\mathrm{PhD}$ context, the use of the term 'customer' is somewhat dubious. While it can be argued that the student could be considered to be the customer, in that they are the ones directly receiving the 'service' of supervision, it is also feasible to consider them to be 'work in progress' as their skills, knowledge and understanding of the research process are developed through the term of their PhD. Both Wood (1997) and Svensson (2007) explore this issue in greater depth.

" "The customer often takes part directly in the production of a service" (Bergman and Klefsjö, 1994). Thus the ultimate success of the service depends on the input of the customer to allow the service provider to effectively meet their needs. A useful analogy is legal advice, where, if the client does not provide all the relevant information, the lawyer may draw mistaken conclusions about the situation and therefore offer inappropriate advice. A further analogy might be that of a health/sports club where access to equipment and trainers achieves nothing unless the client actually performs the suggested exercises.

Clearly, the student's involvement in the $\mathrm{PhD}$ is an inescapable and obvious fact. They have an undeniable responsibility for their own success. However, it is very important that all parties recognise that a rewarding and successful $\mathrm{PhD}$ experience can only be achieved through true collaboration wherein each individual, whether student or supervisor, understands and plays their own role. Furthermore, where a community of $\mathrm{PhD}$ students exists, even where they are not working within a larger project team, the mutual encouragement that arises from a shared understanding of the $\mathrm{PhD}$ experience can provide a valuable extra layer of support to the individual. The graduate schools that have started to emerge in some UK universities over the past decade provide a valuable nexus for $\mathrm{PhD}$ students to form communities of practice, while also offering a centralised conduit for some elements of research skills training which removes a significant task from supervisors and thus allows them to concentrate more of the specific support needed by individual $\mathrm{PhD}$ candidates.

\subsection{The unknown service or supplier}

"Services are activities or processes and cannot therefore be tested by the customer before they are bought" (Bergman and Klefsjö, 1994). In addition, "services cannot be stored to meet fluctuations in demand" (Lewis, 2007). The establishment of a supervisory 
relationship is a high-risk element of the process, particularly for the student, but also (though students rarely consider this) for the supervisor, because when $\mathrm{PhD}$ students fail to achieve, for whatever reason, criticism may be levelled at the supervisors and their reputation can be damaged. Halse's (2011) paper also highlights this issue.

Given the previous discussion of candidates' misunderstanding of what a $\mathrm{PhD}$ is, it is hardly surprising that they rarely have a real appreciation of what they need in a supervisor, nor what service they can expect to receive. Thus, the criteria they apply to the selection of a supervisor (or university) may bear little relation to their actual needs as potential $\mathrm{PhD}$ students. Nor is it really possible to offer a standard person specification for the role, because while there are some core characteristics and actions (as discussed in Phillips and Pugh, 2010), there is a need to adjust these depending on the needs and personality of the student and the investigation being undertaken. Many of the examples given by Phillips and Pugh (2010) serve to reinforce this observation by showing how misaligned expectations can undermine the satisfaction of students and supervisors alike. This is further highlighted by Gibney's (2012) recent article discussing how social media such as Twitter are allowing doctoral students to establish an effective community of practice to supplement formal supervision and plug gaps in the support that they receive.

\subsection{Finding supervisors}

There are several ways in which a student may be linked with a team of supervisors. The author has had experience of three in particular.

The first is where a programme of work has been defined as part of a funded research project. A research post is advertised in the expectation that the person appointed will deliver the investigation required by the contract, while at the same time, being given the opportunity to study for their own $\mathrm{PhD}$. Here, it is usual for the $\mathrm{PhD}$ to be aligned to the contracted project, though the overlap between the two may only be partial. The author's own $\mathrm{PhD}$ followed this pattern, with about $60 \%$ of her $\mathrm{PhD}$ activity also contributing to the work she was being employed to do on the funded project. There are tensions here between the demands of the contract and the individual's study and these can be accentuated where a supervisor is also the student's line manager. Clearly, this potential may be avoided by ensuring a complete separation of personnel for the candidate's two roles as employee and student, though this may not always be possible within the constraints of supervisory expertise, experience and availability. Approaches vary, even across departments within the same university. But it is unlikely that the student will have much say in who supervises them; the decision will be made by the university when the student is appointed to the research post.

The second way to seek a supervisor is by reputation. Potential students may hear of an individual's expertise through reports from friends and colleagues or, more indirectly, via conferences or publications. In some cases, they may know someone who was previously supervised by that person and so is able to report first hand on their own experience. The best case scenario is when student and supervisor have an established academic relationship through a previous course, for example, the supervision of an MSc dissertation. This means that both parties have a good appreciation of the other's abilities and style, and of the effectiveness of the synergies between them.

Thus, the applicant has some true knowledge of the previous performance of at least one of their potential supervisors and has chosen to apply to them for that reason. From the student's viewpoint, this is probably the safest way of 'acquiring' a supervisor. It has 
the added benefit that the supervisor knows that this is why they have been approached, which fosters a positive relationship with the new student right from the start. Where they have worked together before, there is the added benefit that the relationship is based on an already firm foundation and many of the typical 'growing pains' are avoided. Also the student is likely to have confidence in the supervisor's recommendations for secondary supervisors.

However, there may be a negative side to this targeting of a potential supervisor, in that sometimes a supervisor is approached by a student who wants to work with them so much that they either do not take into account that their topic falls outside the area of interest of the supervisor (because they do not understand the importance of subject expertise) or simply insist that they will do whatever the supervisor wants. This latter position is, in this author's view, a very dangerous one, because a student who does not engage in the process of defining their own $\mathrm{PhD}$ study also may not acquire a strong sense of ownership of the work: a situation that can limit the development of the necessary level of independence. This is also a risk for PhDs linked to pre-defined projects.

The third way is when the applicant prepares their own proposal and targets a particular university faculty, presumably because of some knowledge of its reputation, but without knowing about the particular interests and specialisms of the academics therein. The applicant's only opportunity to assess their potential supervisors is during the interview process. In essence, this is a version of the first method, but without the focus given by the pre-defined project, though the student's ownership of the proposal is beneficial.

Consideration of these three ways of obtaining a supervisor suggests that the second is the only one in which the student really has any evidence in advance of the capability of the supervisor and the manner in which they will supervise.

\section{The stakeholders}

In keeping with many activities in the public sector in general, education, and, in particular, the $\mathrm{PhD}$, does not have a single, clearly defined customer, but rather is attempting to satisfy the needs of a wide spectrum of stakeholders with quite disparate needs, all of whom have an interest in the performance and outcome of the activity. This may place additional tensions on the service relationship. For the $\mathrm{PhD}$, the central ones are the student and the supervisor. Other stakeholders may include the University where the student is enrolled, any organisation that is funding the research and potentially the student's employer.

Clearly, the student's primary interest is to receive the award of a $\mathrm{PhD}$, though it is to be hoped that there will also be a desire to gain competence in research skills as the first step in a research or academic career. However, this is often a minor driver, particularly in the case of students from outside the UK. This is because the $\mathrm{PhD}$ is viewed rather differently in some other countries. For example, for the students in the collaborative scheme that the author managed in Egypt, gaining the $\mathrm{PhD}$ was a critical hurdle that must be cleared in order to gain promotion. So, for many of these students, the focus was on gaining the award, rather than developing research skills. Even so, it was impossible to differentiate between those who had a wider developmental interest in their $\mathrm{PhD}$ opportunity and those who were only focussed on the award at the point of application. It 
only became apparent when one got to know the students. This can lead to a mismatch of expectations between student and supervisors, so it is very important that expectations are discussed openly very early in the relationship. This allows the supervisor to try to show an award-focussed student what they are missing and stimulate them to take advantage of the learning potential of the $\mathrm{PhD}$.

\section{Other stakeholder influences}

The university's interest is in successful completion in a timely fashion because this will positively influence both funding and reputation. However, from the management perspective, the 'bread and butter' of university activity and funding is the undergraduate student. Thus pressure may be brought to bear, either explicitly or indirectly, to move academic resources towards class contact, rather than the highly staff-intensive $\mathrm{PhD}$ supervision activity. There is a further tension for the supervisor, who has to balance the development of their own career, the workload demands of their faculty and the academic needs of the $\mathrm{PhD}$ student. Consequently the quality of the $\mathrm{PhD}$ experience for both student and supervisor is threatened. This, of course, leads to the questions 'How much supervision should a PhD student expect?' and 'How much supervision does a successful $P h D$ need?', which of course, link back to the earlier discussion about expectations. Both questions are beyond the scope of this paper and so will only be considered very briefly.

The student's expectation will depend on factors such as prior pedagogic and educational experience, especially on the way in which their previous undergraduate or MSc dissertation was supervised, and upon what they have heard from other students. Their work experience may lead them to expect supervision to resemble line management in a typical business situation. Moreover, there is a link between the project management skills of both members of the supervisory partnership and success. Thus there will be a need for supervisors to discuss the matter to expose any expectation gap and close it. In an absolute sense, this does not impact on the quality of the $\mathrm{PhD}$ experience, but since customer perception is significant in the assessment of quality, it must be considered.

However, the second question is much more significant, even though it may not be directly influenced by student expectation. This author does not believe that there is any absolute answer to this question because every combination of student, investigation and supervisory team demands different levels of supervision to achieve success. Furthermore, this will alter as the $\mathrm{PhD}$ progresses. Supervision will typically be fairly intensive with high levels of direct contact in the early stages, relatively sparse in the experimental/data gathering phase, and quite busy, though often via the exchange of notes on drafts of the thesis, during the final stage. The trick is to find a balance that gives the student adequate support while allowing the supervisor time to provide satisfactory input as demanded by their professional assessment of the student's needs, but within the resource constraints placed upon them. This is further explored by Halse (2011).

The range of sources of funding is very wide; from major commercial research grants at one end, to individual students funding their own studies at the other. The funder's interest is typically in the outcomes of the research itself, rather than in the award of the $\mathrm{PhD}$, though this is by no means clear cut and will vary according to the type of funder. Where the funder is the student or their employer who wishes to support their academic and professional development, the target is typically enhanced skills and employability, evidenced by the award of the degree. Nevertheless, the employer/funder may also have 
an interest in any findings being applied within the organisation, or may be planning to exploit the Intellectual Property Rights of those findings. While the actual details of the funding are strictly out with the remit of the supervisors, they may have a significant impact on the stakeholders and so should be taken into account.

It is reasonable to view the academic community and society in general as stakeholders because of the concept of 'contribution to knowledge' that is at the very heart of the PhD. However, while some members of the academic community will become aware of such contributions from $\mathrm{PhD}$ studies, primarily through the conduits of academic publishing, for the most part, society in general will remain oblivious to the student's very existence, let alone the value of their work. Nevertheless, the generation of competent new researchers is fundamental to ensure the continued development of knowledge, whatever the domain. Clearly, the UK's Higher Education Academy sees the development of new academic talent as part of its remit, as it highlights on its website, but the provision of the next generation of academics is not sufficient; UK plc will need new blood to step into the roles vacated by those lost through natural wastage and severance schemes.

\section{What is in it for the supervisor?}

The deliverables for the supervisor are quite varied. There are the normal 'rewards' that come from teaching, such as the satisfaction of observing the intellectual development of the student. The enjoyment and challenge of shared debate about the research topic, especially when the student is working on a topic that is central to the supervisor's interests. Then there are the more tangible elements, such as receiving credit for successful completions and the generation of material for journal or conference papers, jointly authored with the student. Where the studentship arises from a funded research project, there may also be financial rewards in the sense of an enhanced likelihood of gaining further funding for research areas that the supervisor wishes to develop. All of these may enhance the career development potential of the supervisor.

\section{Characteristics of a supervisory team}

Within UK academia, the leader of the supervisory team is often known as the director of studies', a title that certainly has the potential to lead to a misunderstanding of their role. This is because it carries connotations of command and control over the student. However, it can be argued that this perception is not only mistaken but inappropriate because a key dimension of the $\mathrm{PhD}$ candidate's development is the ability to design, manage and critically evaluate their own work independently. This view is supported by Pearson and Brew (2002). However, where the $\mathrm{PhD}$ arises from or is related to a programme of contracted research, as discussed previously, some tensions may develop.

In the opinion of this author, shaping the study should be a joint activity, with the student providing the ideas and the supervisory team showing them how to make those ideas into a manageable, properly bounded study that is likely to be achievable within the time and resource constraints of a $\mathrm{PhD}$, while also having the potential to deliver the necessary research experience and novelty. The extent to which this can be done is dependent on the subject area, but in the author's experience, achieving student 
ownership of the work right from the start has a major impact on the likelihood of completion. For this reason, she tends to prefer the term 'mentor'. Indeed, it would be possible to characterise the complete $\mathrm{PhD}$ supervisory team as a 'mentoring circle' as discussed by Darwin and Palmer (2009), wherein all parties both provide support and learning opportunities to the others and also benefit from that which is proffered by their colleagues. Truly, a win-win situation that is perhaps under-recognised as a developmental activity for supervisors, not just students. This mechanism offers a means of organisational learning as 'experts' pass on tacit knowledge by means of practical demonstration (Lam, 2000).

It is vital that there is a level of trust and respect between the parties. If not, the student will fail to benefit from the greater knowledge of their supervisors and, ultimately, may well not gain the qualification they seek. A student who gives lip service to respecting the value of their supervisor's advice, but does not act on it, is simply wasting everyone's time and effort and damaging their own chances of success. This is not to say that the supervisor is always right, nor that their direction should always be followed, but rather that differences of opinion are a learning opportunity that must be explored through proper academic debate, so that a valid, acceptable and defensible view may be reached. Lee (2008) and Franke and Arvidsson (2011) further explore supervisor views on achieving this intellectual emancipation.

There is another relationship which must work effectively. This is the one between the supervisors. A friendly, respectful interaction between the supervisors, especially when they are in disagreement about some issue, is important as it sets an example to the student of the way in which professionals may present differing views and debate them to come to a consensus. The student learns by observation and gradually gains the confidence to join in and present their own arguments. Such debate between supervisors also serves to open the student's eyes to alternative possibilities to those that they perceive as obvious. This is an important developmental point because new PhD students often have a rather narrow view of situations and potential responses, whether they are activities or conclusions.

A poor working relationship between supervisors can have a major impact on the student. On one occasion, the author, in her role as DoS, had agreed with both student and second supervisor a plan of work for the coming month, when she would be away from the university. On her return, she discovered that shortly after she had left, the second supervisor had summoned the student and instructed him to do something different. The student, feeling unable to demur, did as he was told. The result was a considerable amount of misdirected and unnecessary work for the student, resulting in delayed submission. There was a complete breakdown of trust between the second supervisor and the student and DoS, to the point where the student declared his unwillingness to continue to work with the second, so that he was effectively excluded from the supervision and was replaced.

The second supervisor concerned was a novice who had been allocated to the team to gain experience from working with the much more experienced DoS. However, he came from a cultural background where it was not the norm for a man to take a secondary role to a woman and he often attempted to overrule her views, not via academic debate, but by forceful insistence on having his own way. Furthermore, he believed that his role as a supervisor was to decide on both the direction and methods of the research, so that the student was only to work as he directed, thus denying the student the developmental 
opportunities that are the very core of the $\mathrm{PhD}$ experience. This is not simply a difference of supervisory style. Here, there are two critical issues:

1 that the novice ignored what had been agreed and simply overturned previous plans, without even having the courtesy of advising the other supervisor, let alone discussing the changed direction with her and the student

2 the direction he demanded was in pursuit of his own research interests, despite a lack of relevance to the student's work.

Learning how to become an effective supervisor is not something that can be taught via classes or books. Like the $\mathrm{PhD}$ itself, developing supervisory skills is best achieved through practical experience under the mentoring of an experienced colleague. Indeed, while some universities in the UK require that supervisory teams are 'qualified' by the inclusion of someone who has achieved some fixed number of successful $\mathrm{PhD}$ completions, this is not universal (Powell and Green, 2012). The intention is to provide a core of expertise that relates to supervision, as opposed to subject matter, but also means that the experienced supervisor actually has two separate training roles to perform: one for the student and the other for the novice supervisor. Thus it can be seen that there is actually a two- layer apprenticeship as an individual moves from $\mathrm{PhD}$ student, to novice supervisor and thence to experienced supervisor. This author's first two supervisions were partnered with her own second supervisor. This meant that a good working relationship had already been established, she understood his supervisory style, but also had confidence that he would accept a difference of opinion as an opportunity to explore the options and give a new learning experience to the students, and not as a challenge to his authority. This was the complete antithesis of the author's experience with the novice supervisor described above. Although there is a risk of 'in-breeding' in that perhaps there may be too little variety in approach and view to challenge the student, this is likely to be avoided when the supervisors trust one another sufficiently to deliberately espouse contrary views to help the student learn how to engage in academic debate. Working with a variety of supervisory partners provides stimulation for the supervisor and exposes them to different styles and hence helps them to continue to develop and enhance their supervision activities, thus making supervision a learning experience in skills, as well as subject, thereby enhancing the quality of the experience as well as the performance of supervision.

In several cases, the author had to continue a supervision alone when another team member became inactive part-way through the registration period. Although, in an ideal world, these supervisors should have been replaced immediately, political or resourcing issues, over which the remaining supervisor has no control, may prevent this. While, in her experience, this is not a fundamental factor in determining student success, she believes that it does weaken the student's experience of academic debate and it certainly makes the lone supervisor's job much more taxing, although it does tend to significantly strengthen the relationship between supervisor and student.

In this author's experience, the early establishment of a real relationship between student and supervisor is absolutely critical. She has had positive experiences in supervising students admitted via the first and second routes previously discussed. However, in two cases, following the retirement of the original director of studies, she was compulsorily appointed to take over the supervision of students with whom she had not previously been involved. Both were studying part-time and were around two years 
into their studies. It later transpired that the remaining supervisors were making little contribution to the supervision. In both cases, the students had strong, if ill-informed, views about their work, but were disinclined to truly engage with her supervision to explore and enhance those views. Sadly, despite concerted efforts to establish an effective working relationship with these students, plus attempts to provide extra support to compensate for the other supervisors' lack of input, neither student gave more than lip service to her advice and, ultimately, both failed to achieve their desired outcome, to the disappointment of all concerned. From the supervisor's viewpoint, there were the additional frustrations that these students, because of their unwillingness to cooperate, damaged her supervisory reputation and undermined her confidence in her supervisory ability to the extent that she seriously considered giving up supervision; they took more effort to supervise than any of her other $\mathrm{PhD}$ students, and, because of their addition to her workload, prevented her accepting a highly committed and competent student that she wanted to take on at that time. When considering the impact of this situation on the quality of the $\mathrm{PhD}$ experience, it can clearly be seen as negative from the perspective of both student and supervisor, and also had some impact on other students because of the additional workload that these two students caused. This observation is consistent with the findings of Ives and Rowley's (2005) study.

On occasion, the relationship between student and supervisor will deepen into one of true friendship and, when this happens, it takes the rewards accruing from the $\mathrm{PhD}$ to another level, where student and supervisor may continue both academic and social interactions over many years. Indeed, several of Lee's (2008) respondents express similar sentiments. With one of her former students, such a relationship has, to date, continued for some 15 years beyond the award of the $\mathrm{PhD}$. Indeed, they are now engaged in their first joint PhD supervisions. These current students were both graduates of an MSc programme on which the supervisors provide considerable input. Thus, not only is there a strong working relationship between the supervisors, but this is reinforced by the students having confidence in, and respect for, the capability of the supervisors. Both students are developing well and are already (both are about half of the way thorough their studies) well on the way to interacting with their supervisors as peers. In addition, both supervisory teams include a novice third supervisor, each of whom previously taught the student concerned, was interested in the student's proposed study and wanted to become involved. Both are proving to be a valuable addition to the team and both seem to be enjoying this new professional challenge.

\section{The emotional dimension}

Another facet of the student's development that must be monitored is their emotional reaction to the $\mathrm{PhD}$ experience. During a $\mathrm{PhD}$, the student's perceptions and intellectual reactions to new experiences are stretched and challenged repeatedly and this can have a serious impact on their emotional stability and self confidence. This author has observed two particular danger points during the process, which, if not managed appropriately, create a very real risk that the student will abandon their studies, so guiding the student through these danger points is a key factor in enhancing the quality of the $\mathrm{PhD}$ experience.

Considering the traditional three year, full-time duration, there is typically a crisis of confidence about a year into the study. This tends to occur in the late stages of the 
literature review, when the student has to commit to their final research objectives and start to plan the investigative/experimental phase. Often the student becomes overwhelmed by the task ahead of them because they have finally come to understand just what they have let themselves in for in attempting a $\mathrm{PhD}$. Some students become almost paralysed and waste enormous amounts of effort dithering about how they should progress their study, being unable to commit to a decision that will fix their direction for the remainder of their study.

The second danger point tends to occur during the write-up phase and is characterised by the student expressing significant levels of doubt about the value of their work. Curiously, it is often the strongest candidates who are most troubled by such doubts. This is a high-risk phase of the $\mathrm{PhD}$ because it can easily result in the student abandoning their work and walking away from the $\mathrm{PhD}$. Thus the supervisor needs to be alert to recognise the symptoms and take action to bolster the candidate's confidence by bringing them to a more realistic view of the value of what they have done, contextualised by the expectations of a $\mathrm{PhD}$. Students studying part-time also exhibit these behaviours at proportionately the same stage in their studies as their full-time brethren, although the symptoms may be harder for the supervisor to spot because of the lower level of direct contact, especially where the student is a Distance Learner. As a result of the extra isolation that is a concomitant of part-time study, sensitive and active support from the supervisor is particularly important.

The author has taken to warning her students about these 'humps' and has found that they now tend to recognise what is happening to them fairly quickly and soon come to her to debate the way forward. Their approach is usually along the lines of 'You told me this might happen, so this is how I am trying to deal with it...'. At these points, the supervisor's input typically needs to focus on rebuilding the student's confidence, rather than actually giving much academic direction, though occasionally it may require a degree of encouragement that verges on bullying to push them into making a decision and moving forward. However it is done, the student needs sensitive handling to make it past these danger points and the choice of a method to help them rests firmly on the quality of the relationship and understanding that have already been developed between student and supervisor. The critical goal at such times is to help the student to learn techniques that will allow them to deal with similar situations in the future on their own.

The student-supervisor relationship alters significantly as the $\mathrm{PhD}$ progresses and is, in many ways, analogous of the parent-child relationship, wherein the parent seeks to protect and guide the child until they have the capability to become independent. Typically, the student will be quite dependent to start with, though the author feels strongly that the student should always be the 'owner' of the research because this builds their commitment to a successful outcome. In the early stages, students tend to await instruction and defer to the supervisors in all debates, but gradually they become more confident in their own opinions and become better able to express and justify their own views and the relationship becomes more of an equal partnership, until, eventually, they are leading the process with the supervisors simply providing underpinning support and the occasional 'wake-up call' to bring to the attention of the student some issue that they have overlooked. Thus the student's confidence and ability to defend their research develops to the point of writing and defending their thesis against whatever challenges are presented by their examiners. 


\section{Conclusions}

This paper has explored a variety of issues that occur during the service relationship of a $\mathrm{PhD}$ study. The author's view is that making the $\mathrm{PhD}$ a quality experience is not simply a matter of increased regulation, but instead must focus on the relationship between student and supervisory team. This is the key component of success.

Often, the relationship between student and supervisors commences as a simple 'marriage of convenience', with neither side having much opportunity for a proper 'courtship'. Thus, a very important task for the early days of the relationship is for both sides to explore one another's expectations and preconceptions. It is important to ascertain the drivers and characteristics of success of the various stakeholders, because this will influence the activity and the supervisory relationship. Furthermore, it must not be forgotten that a $\mathrm{PhD}$ is not only an intellectual journey for the student, but also one requiring emotional engagement and change. The manner in which student and supervisors relate to one another cannot be pre-defined, but will be influenced by experience, culture and personality: every supervision is different because every student and supervisor is different! The issue of supervisory training has not been considered in this paper because it is a large topic in itself and has therefore been left for a future paper.

It is interesting to note, however, that in this particular dataset, neither native language, study mode nor locality seem to have any direct impact on outcome, though it does seem that changes in supervision and gender could have some significance with respect to the students who withdrew. It is notable that all four who went to full term but did not then submit were students who were simply allocated to supervisors, with three of these involving the compulsory introduction of a new supervisor part way through the study period with no choice being given to either student or new supervisor. This may therefore be seen as a weak point in the development of the service relationship between these new partners. Furthermore, where there was an imposed supervisor, there is a need to revisit steps two and three of the service agreement to ensure that a common view of the service has been established.

For the most part, this paper has been the outcome of one academic's developmental journey from fresh $\mathrm{PhD}$ student in the late 1980s, to experienced and enthusiastic supervisor some 20 years later. Her purpose in writing the paper was to offer her experience to stimulate debate among her peers with a view to giving the next generation of $\mathrm{PhD}$ students and supervisors a better quality experience. Clearly, it would be desirable for further research to analyse additional supervisory career cases to provide a more robust data set.

\section{References}

Bergman, B. and Klefsjö, B. (1994) Quality from Customer Needs to Customer Satisfaction, McGraw-Hill Book Company, Europe.

Bryman, A. and Bell, E. (2011) Business Research Methods, 3rd ed., Oxford University Press, Oxford, UK.

Darwin, A. and Palmer, E. (2009) 'Mentoring circles in higher education', Higher Education Research and Development, Vol. 28, No. 2, pp.125-136.

Franke, A. and Arvidsson, B. (2011) 'Research supervisors' different ways of experiencing supervision of doctoral students', Studies in Higher Education, Vol. 36, No. 1, pp.7-19. 
Gibney, E. (2012) 'Research intelligence - the doctor will advise you now', Times Higher Education, 24 May [online] http://www.timeshighereducation.co.uk/story.asp?sectioncode= 26\&storycode $=420033$ (accessed 21 June 2012).

Halse, C. (2011) 'Becoming a supervisor': the impact of doctoral supervision on supervisors' learning', Studies in Higher Education, Vol. 36, No. 5, pp.557-750.

ISO (1994) ISO 8402 Quality Management and Quality Assurance-Vocabulary, ISO, Geneva.

Ives, G. and Rowley, G. (2005) 'Supervisor selection or allocation and continuity of supervision: PhD students' progress and outcomes', Studies in Higher Education, Vol. 30, No. 5, pp.535-555.

Lam, A. (2000) 'Tacit knowledge, organisational learning and societal institutions: an integrated framework', Organization Studies, Vol. 21, No. 3, pp.487-513.

Lee, A. (2008) 'How are doctoral students supervised? Concepts of doctoral research supervision', Studies in Higher Education, Vol. 33, No. 3, pp.267-281.

Lewis, B.R. (2007) 'Managing service quality', in Dale, B.G. et al. (Eds.): Managing Quality, 5th ed., pp.234-257, Blackwell, Oxford.

Mullins, G. and Kiley, M. (2002) 'It's a PhD, not a Nobel Prize', Studies in Higher Education, Vol. 27, No. 4, pp.369-386.

Pearson, M. and Brew, A. (2002) 'Research training and supervision development', Studies in Higher Education, Vol. 27, No. 2, pp.135-150.

Phillips, E. and Pugh, D.S. (2010) How to get a PhD: A Handbook for Students and Supervisors, 5th ed., Open University Press, UK.

Powell, S.D. and Green, H. (2012) 'Quality matters in doctoral supervision - a critique of current issues in the UK within a worldwide context', Postgraduate Directions [online] http://www.postgraduatedirections.org.uk/whatsNew.html\#idPaper240408a (accessed 21 June 2012).

Svensson, G. (2007) 'Are university students really customers? When illusion may lead to delusion for all!', International Journal of Education Management, Vol. 21, No. 1, pp.17-28.

Wood, M. (1997) 'The notion of the customer in total quality management', Total Quality Management and Business Excellence, Vol. 8, No. 4, pp.181-194.

\section{Appendix}

\section{Descriptive statistics}

This paper is based on the author's experiences through a career encompassing the supervision of $18 \mathrm{PhD}$ students, with the last two of these being at the midpoint of their studies at the time of writing. Thus the paper is primarily based on those 16 students who either successfully completed their studies and earned their $\mathrm{PhD}$, or withdrew from the process without being examined. These 16 students were registered at the author's previous university. Study durations were, on average, well within the permitted maxima, though a few students were delayed by serious family circumstances. While the author is female, all other supervisors were male with the exception of those involved with the two currently active students, who are all female. During the past 20 years, the author has assessed the applications of more than 50 potential $\mathrm{PhD}$ students.

With regard to those students who failed to complete, four of the five students did not complete their thesis and failed at this final hurdle. The other was unable to secure the necessary funding and so was forced to withdraw during the first year of his studies. It is worth noting that the two overseas distance learners (ODLs) (see below) who ultimately 
withdrew without completing chose not to make the recommended number of study visits.

UK-based part-time students followed a traditional part-time supervision regimen, working remotely with electronic support, but having face-to-face supervisory meetings at approximately monthly intervals. Full-time students also had monthly supervisory meetings, but were based within the university and so had additional opportunities for ad-hoc meetings.

ODLs studied part-time but with block release intensive study periods. The preponderance of Arabic speakers among the ODLs was a consequence of a partnership agreement between a UK and an Egyptian university that was sponsoring their staff to undertake part-time PhDs at several European universities. Students were based at the Egyptian university for the bulk of their registration and supervised electronically. However, they were expected to make two visits per annum, each of two to four weeks' duration, to work intensively with their supervisor in the UK. During these visits, it was common for the students to make dramatic progress with their studies. These visits were supplemented by the author (who also managed the scheme) making visits to Egypt twice a year. A total of 17 students studied under this scheme and $15 \mathrm{PhDs}$ were awarded.

Table 1 Descriptive statistics

\begin{tabular}{|c|c|c|c|c|c|c|c|c|}
\hline \multirow{3}{*}{$\begin{array}{l}\text { Status } \\
\text { Gender }\end{array}$} & \multicolumn{2}{|c|}{$\begin{array}{c}\text { Awarded PhD } \\
11\end{array}$} & \multicolumn{2}{|c|}{$\begin{array}{c}\text { Did not complete } \\
5\end{array}$} & \multicolumn{2}{|c|}{$\begin{array}{c}\text { Active } \\
2\end{array}$} & \multicolumn{2}{|c|}{$\begin{array}{c}\text { Overall } \\
18\end{array}$} \\
\hline & Male & Female & Male & Female & Male & Female & Male & Female \\
\hline & 6 & 5 & 4 & 1 & 1 & 1 & 11 & 7 \\
\hline \multirow{2}{*}{$\begin{array}{l}\text { Author's } \\
\text { supervisory role }\end{array}$} & DoS & $2 \mathrm{nd}$ & DoS & $2 \mathrm{nd}$ & DoS & 2nd & DoS & $2 \mathrm{nd}$ \\
\hline & 5 & 6 & 2 & 3 & 1 & 1 & 8 & 10 \\
\hline \multirow{2}{*}{$\begin{array}{l}\text { Knowledge of } \\
\text { supervisor }\end{array}$} & A & $\mathrm{C}$ & A & $\mathrm{T}$ & A & $\mathrm{C}$ & A & $\mathrm{T}$ \\
\hline & 4 & 6 & 4 & 1 & & 2 & 9 & 3 \\
\hline \multirow{2}{*}{$\begin{array}{l}\text { Supervisory } \\
\text { changes? }\end{array}$} & No & Yes & No & Yes & No & Yes & No & Yes \\
\hline & 9 & 2 & 2 & 3 & 2 & & 13 & 5 \\
\hline \multirow[t]{2}{*}{ Study mode } & $\begin{array}{l}\text { Full } \\
\text { time }\end{array}$ & $\begin{array}{l}\text { Part } \\
\text { time }\end{array}$ & $\begin{array}{l}\text { Full } \\
\text { time }\end{array}$ & $\begin{array}{l}\text { Part } \\
\text { time }\end{array}$ & $\begin{array}{l}\text { Full } \\
\text { time }\end{array}$ & $\begin{array}{l}\text { Part } \\
\text { time }\end{array}$ & $\begin{array}{l}\text { Full } \\
\text { time }\end{array}$ & $\begin{array}{l}\text { Part } \\
\text { time }\end{array}$ \\
\hline & 1 & 10 & 1 & 4 & 1 & 1 & 3 & 15 \\
\hline \multirow{2}{*}{ UK or ODL } & UK & ODL & UK & ODL & UK & ODL & UK & ODL \\
\hline & 4 & 7 & 3 & 2 & 1 & 1 & 8 & 10 \\
\hline \multirow{2}{*}{$\begin{array}{l}\text { Native } \\
\text { language }\end{array}$} & English & Arabic & English & Arabic & English & Arabic & English & Arabic \\
\hline & 3 & 8 & 3 & 2 & 1 & 1 & 6 & 12 \\
\hline
\end{tabular}

Note: Prior knowledge of supervisor

Key: A = Supervisor appointed, student did not know supervisor

$\mathrm{C}=$ Requested a supervisor who had supervised colleague or friend

$\mathrm{T}=$ Requested a supervisor who had previously taught them 